\title{
Pengenalan ecoprint guna meningkatkan keterampilan siswa dalam pemanfaatan bahan alam
}

\author{
Nindita Clourisa Amaris Susanto ${ }^{1}$, Madyawati Latief ${ }^{2 \star}$, Ratih Dyah \\ Puspitasari $^{3}$, Restina Bemis ${ }^{4}$, Heriyanti ${ }^{5}$
}

${ }^{1}$ Universitas Jambi, Indonesia, email: ninditaclourisa@unja.ac.id.

22Universitas Jambi, Indonesia, email: madyawatilatief@unja.ac.id

${ }^{3}$ Universitas Jambi, Indonesia, email: ratihdyah@unja.ac.id

${ }^{4}$ Universitas Jambi, Indonesia, email: restina@unja.ac.id

5Universitas Jambi, Indonesia, email: heriyanti@unja.ac.id

${ }^{*}$ Koresponden penulis

\section{Info Artikel}

Diajukan: 09 Okt 2020

Diterima: 12 Feb 2021

Diterbitkan: 23 Feb 2021

Keywords:

ecoprint; skill; natural dyes

Kata Kunci:

ecoprint; keterampilan;

bahan alam

Lisensi:

cc-by-sa

\begin{abstract}
Ecoprint is a technique for printing colors and shapes on fabric using natural materials. Ecoprint techniques have been introduced to junior high school students because they can capture the material and teacher's instructions independently, think critically and creatively. The purpose of the ecoprint introduction activity is to provide knowledge about ecoprint and students' skills in utilizing local potential through natural materials or plants around the school. The methods used are lectures, demonstrations, practice, and evaluation. The questionnaires and direct observations on ecoprint products were used as evaluations for this activity. Students have been able to print motifs and colors from leaves and flowers on a cloth to produce ecoprint products according to their respective creativity.

Abstrak

Ecoprint merupakan teknik pewarnaan kain dan pencetakan motif dengan menggunakan bahan alam. Teknik ecoprint diperkenalkan kepada siswa sekolah menegah pertama dan sederajat karena pada usia tersebut anak sudah dapat menangkap materi dan instruksi guru secara mandiri serta mampu berpikir kritis dan kreatif. Adapun tujuan dari kegiatan pengenalan ecoprint adalah memberikan pengetahuan tentang ecoprint dan keterampilan bagi siswa dalam memanfaatkan potensi lokal melalui bahan alam atau tanaman yang ada disekitar sekolah. Metode yang digunakan adalah ceramah, demonstrasi, praktik dan evaluasi. Evaluasi menggunakan kuesioner dan pengamatan secara langsung pada produk ecoprint yang telah dibuat oleh siswa. Siswa telah mampu mencetak motif dan warna dari daun serta bunga di atas kain menghasilkan produk ecoprint sesuai dengan kreativitas masing-masing.
\end{abstract}

\section{PENDAHULUAN}

Ecoprint merupakan teknik pewarnaan dengan mempercantik kain menggunakan bahan alam sekaligus menghasilkan motifnya (Herlina et al., 2018; Utaminingsih \& Wike, 2019). Teknik ini menjadi tren saat ini karena sesuai dengan isu yang sedang naik daun mengenai produksi ramah lingkungan (Saptutyningsih \& Wardani, 2019). Berbeda dengan teknik 
pewarnaan dan cetak motif pada kain yang menggunakan bahan buatan yang dapat memberikan dampak akumulatif terhadap kesehatan dan lingkungan dengan sifatnya yang karsinogen dan membahayakan. Beberapa contoh bahan buatan yang disintetis secara kimia sebagai turunan dari hidrokarbon aromatik yaitu naftol, indigosol dan remasol (Atirza \& Soewondo, 2018).

Bahan alam yang sering digunakan untuk menghasilkan ecoprint seperti daun jati (Saraswati \& Sulandjari, 2018), daun ubi (Wirawan \& Alvin, 2019) dan jenis tumbuhan lainnya yang mempunyai warna kuat (Husna, 2016). Keanekaragaman keterampilan dapat diperoleh siswa di sekolah. Berbagai macam metode yang dapat digunakan untuk memproduksi ecoprint salah satunya yaitu teknik pounding. Metode tersebut merupakan metode yang sederhana dalam aplikasi ecoprint (Arif \& Marsudi, 2019).

Sekolah menegah pertama dan sederajat menjadi pondasi pertama dalam penanaman keterampilan karena pada usia tersebut anak sudah dapat menangkap materi dan instruksi guru secara mandiri serta mampu berpikir kritis dan kreatif. Oleh karena itu kegiatan dilaksanakan di SMP N 10 dan MTs $\mathrm{N} 6$ Muaro Jambi. Berdasarkan hasil observasi dan wawancara dari kedua sekolah tersebut belum pernah mendengar dan mengenal teknik ecoprint. Sehingga melalui kegiatan ini diharapkan dapat memberikan pengetahuan tentang ecoprint dan keterampilan bagi siswa dalam memanfaatkan potensi lokal melalui tanaman yang ada disekitar sekolah.

\section{METODE PELAKSANAAN}

Guna mencapai tujuan kegiatan pengabdian kepada masyarakat ini terdapat beberapa tahapan kegiatan yang dijabarkan sebagai berikut:

\section{Koordinasi Tim}

Koordinasi dengan tim dilaksanakan untuk mempersiapkan materi dan perlengkapan yang dibutuhkan dalam menunjang kegiatan pengabdian kepada masyarakat. Pada saat kegiatan pelaksanaan terjadi pandemi Covid-19 sehingga diperlukan berbagai macam rencana agar kegiatan terlaksana sesuai dengan capaian tujuannya.

\section{Koordinasi dengan SMP N 10 dan MTs $\mathbf{N} 6$ Muaro Jambi}

Tim pengabdian kepada masyarakat melaksanakan koordinasi dengan pihak sekolah terkait dengan peserta yang akan mengikuti kegiatan. Hal tersebut dimaksudkan agarprogram dapat berjalan sesuai rencana dan tujuan dari kegiatan ini dapat tercapai.

\section{Pelaksanaan Kegiatan}

Langkah-langkah yang dilakukan dalam pelaksanaan kegiatan ini antara lain:

a. Sosialisasi

Sosialisasi ini dilakukan untuk pengenalan awal terhadap ecoprint karena kedua sekolah belum mengenal tentang ecoprint. Sosialisasi dilakukan melalui presentasi dari tim pengabdian dan tanya jawab.

b. Pelatihan Pembuatan Produk Ecoprint

Pelatihan dilaksanakan oleh tim pengabdian melalui demonstrasi secara langsung di depan siswa dan guru pendamping. Demonstrasi 
ini meliputi cara pemilihan kain, persiapan daun dan bunga, penataan daun dan bunga pada kain dan pengikatan warna agarwarna dari alam tersebut dapat lebih tahan lama.

c. Praktik Pembuatan Produk Ecoprint

Praktik dilaksanakan siswamenggunakan bahan dan alat yang telah disediakan tim pengabdian. Adanya keterbatasan waktu luring di sekolah maka tim pengabdian berkoordinasi dengan guru pendamping diberikan waktu 3 hari bagi siswa untuk menyelesaikan dan dilakukan lagi pertemuan dengan tim pengabdian untuk melihat hasil yang telah dibuat oleh siswa.

\section{Evaluasi Program}

Evaluasi dilaksanakan dengan kuesioner dan melihat secara langsung hasil karya siswa.

\section{HASIL DAN PEMBAHASAN}

Kegiatan pengabdian kepada masyarakat ini berupa pengenalan dan pelatihan teknik ecoprint bagi siswa di SMP N 10 dan MTs N 6 Muaro Jambi terkait penggunaan bahan alam. Kegiatan ini bertujuan untuk menambah keterampilan siswa terkait teknik membatik sederhana yang ramah lingkungan dan mudah dipraktikkan oleh siswa yaitu teknik ecoprint.

Pada tahap koordinasi antara tim pengabdian dengan kedua sekolah diperoleh hasil bahwa terdapat pembatasan jumlah peserta dan lamanya waktu kegiatan disebabkan masa pandemi Covid-19. Oleh karena itu saat pelaksanaan kegiatan di SMP N 10 Mauro Jambi yang dilaksanakan pada tanggal 25 Juli 2020 dan 1 September 2020 berjumlah 12 peserta yang terdiri dari guru dan siswa. Begitu juga pelaksanaan kegiatan di MTs N 6 Muaro Jambi pada tanggal 28 Juli 2020 berjumlah 15 peserta. Dengan kondisi tersebut tim pengabdian membuat video pembuatan produk ecoprint agar dapat menjadi media pembelajaran bagi guru ditunjukkan pada Gambar 1.

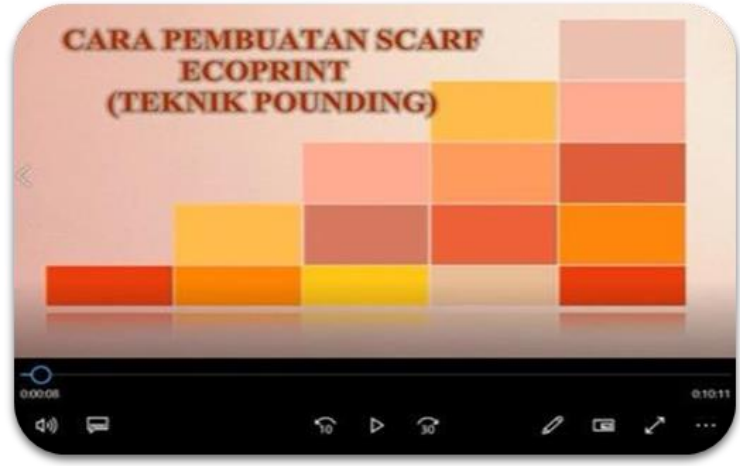

Gambar 1. Tampilan Video Pembuatan Produk Ecoprint

Pada saat sosialisasi, tim pengabdian melakukan presentasi mengenai ecoprint, bagaimana pemilihan kain, bahan alam yang akan digunakan dan tahap fiksasi atau pengikatan warna dan motif bahan alam pada kain 
ditunjukkan Gambar 2. Kegiatan dilaksanakan dari pukul 08.00 WIB. Peserta merespon baik progam ini. Kegiatan dilanjutkan demonstrasi pembuatan produk ecoprint oleh tim pengabdian.

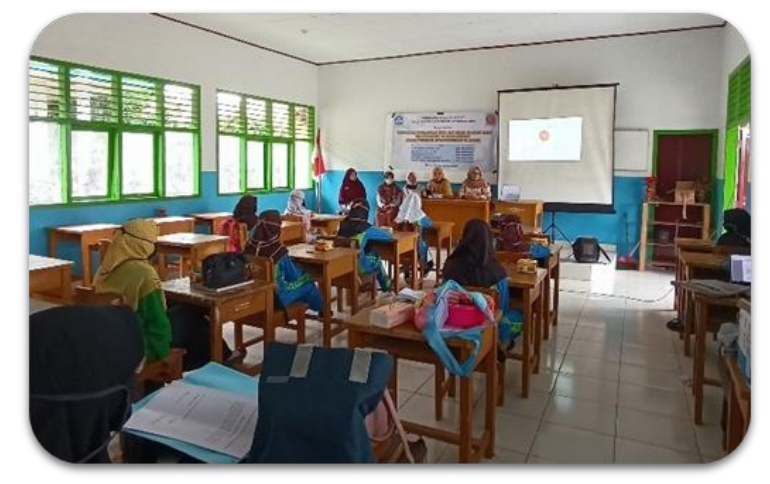

Gambar 2. Kegiatan Sosialisasi Ecoprint

Pelatihan pembuatan produk ecoprint dari bahan alam menggunakan
metode pounding yang didemonstrasikan oleh tim pengabdian ditunjukkanpada Gambar 3 dan dilanjutkan dengan praktek oleh peserta. Dalam pelatihan dijelaskan jenis kain, bahan alam dan bagaimana cara agar warna dan motif dapat menempel dengan baik pada kain. Selain itu, dijelaskan juga mengenai penataan daun di atas kain dan tahap akhir yaitu fiksasi. Tahap fiksasi dapat menggunakan tawas, kapur tohor dan tunjung (Pudjianti, 2019). Pengikatan warnadan motif yang menempel pada kain dimaksudkan agar tidak mudah pudar (Anzani et al., 2016). Perbedaan jenis bahan pengikat akan memberikan arah warna yang dihasilkan dari bahan alam. Fiksasi dengan tawas akan memberikan hasil warna yang sesuai dengan warna aslinya. Fiksasi dengan kapur tohor akan memberikan hasil warna yang lebih tua dari warna aslinya. Sedangkan fiksasi dengan tunjung akan memberikan warna gelap dari hasil cetak warna dan motif yang berasal dari bahan alam (Pujilestari, 2014).

Bahan alam yang digunakan daun jati, daun singkong, daun pepaya, bunga telang. Kain mengandung serat alam dipilih agar warna dan motif dari bahan alam mudah menempel pada kain seperti kain katun. Hasil karya yang diperoleh dari pelatihan ini adalah produk ecoprint dalam bentuk scarf. Pada kegiatan ini siswa yang didampingi oleh guru diberikan ruang kebebasan untuk berkreasi dalam menghasilkan pola dan motif pada kain menggunakan daun dan bunga. 


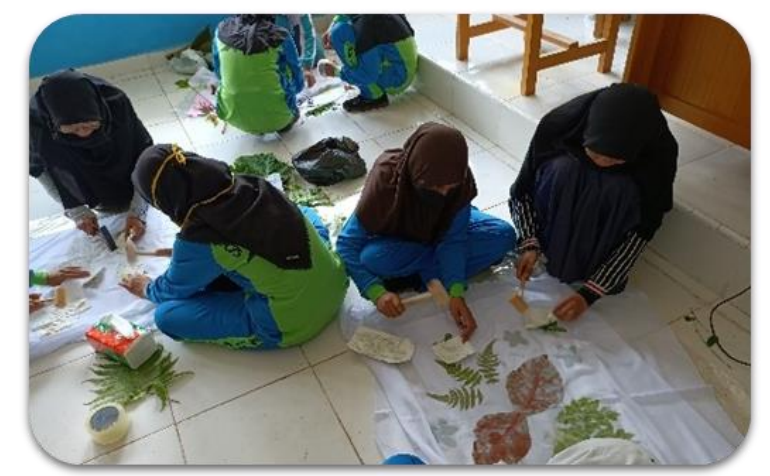

Gambar 3. Pelatihan dan Praktek Pembuatan Produk Ecoprint

Untuk mengetahui tingkat keberhasilan pada kegiatan ini maka tim pengabdian melaksanakan tahap evaluasi. Tahap evaluasi dengan metode pengamatan pada produk ecoprint yang dihasilkan peserta dan kuesioner. Dari hasil kuesioner untuk evaluasi kegiatan dari peserta yang berjumlah 12 untuk SMP N 10 Muaro Jambi dan 15 peserta untuk MTs N 8 Muaro Jambi terkait kebermanfaatan kegiatan, penyampaian materi, peralatan pendukung yang disediakan, praktik kegiatan dan hasil karya dari pelatihan disajikan pada Gambar 4. Gambar 4 menunjukkan penilaian rata-rata dari peserta untuk setiap aspek pada 2 sekolah yang berbeda. Skor 1 menunjukkan sangat tidak baik, skor 2 menunjukkan tidak baik, skor 3 menunjukkan cukup, skor 4 menunjukkan baik dan skor 5 menunjukkan sangat baik. Pada aspek kebermanfaatan kegiatan dari peserta di dua sekolah diperolah skor sangat baik. Aspek tersebut menunjukkan kegiatan ini menambah keterampilan yang dimiliki siswa. Dari semua aspek yang dievaluasi rata-rata menunjukkan skor lebih dari 4 dimana menunjukkan kegiatan ini dapat berjalan dan diterima dengan baik. Berdasarkan hasil evaluasi kegiatan yang telah dilaksanakan saat ini, besar harapan sekolah untuk dapat dilaksanakan keberlanjutan program ini karena bermanfaat bagi siswa dan sekolah.

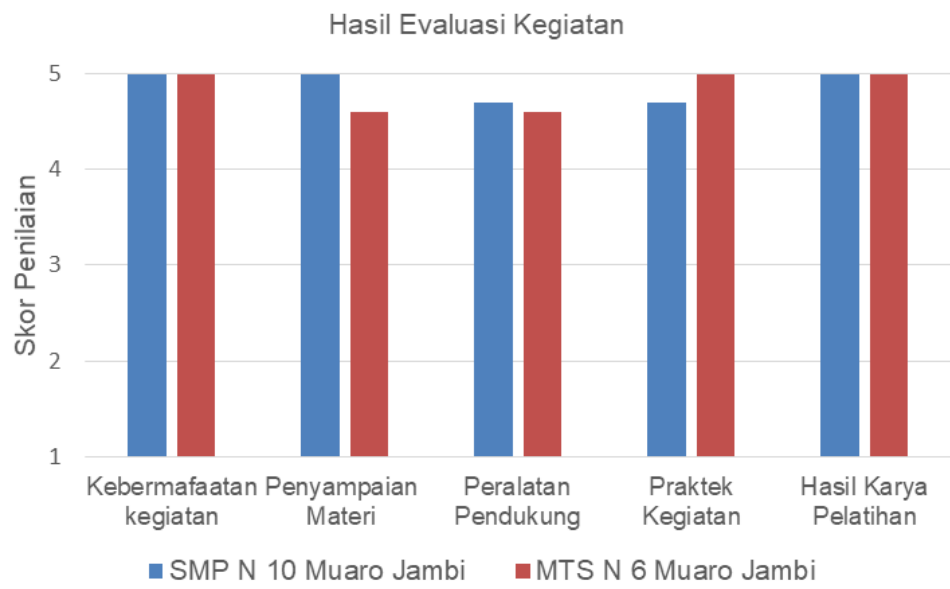

Gambar 4. Hasil Evaluasi Kegiatan 


\section{KESIMPULAN}

Kegiatan pengabdian kepada masyarakat telah berhasil dilaksanakan dan berjalan lancar. Keberhasilan dari kegiatan dapat dilihat dari antusias peserta dan hasil evalusi terhadap kegiatan yang dinilai baik bahkan sangat baik untuk beberapa aspek. Siswa mempunyai keterampilan tambahan dalam kaitannya penggunaan bahan alam untuk memperoleh produk yang ramah lingkungan yaitu ecoprint. Untuk selanjutnya perlu eksplorasi lebih lanjut terkait ecoprint dan pengembangan produknya.

\section{UCAPAN TERIMA KASIH}

Terima kasih kami ucapkan kepada SMP N 10 dan MTs N 6 Muaro Jambi yang telah memberikan izin dan mendukung penuh pelaksanaan kegiatan pengabdian kepada masyarakat ini. Selanjutnya ucapan terima kasih kepada Lembaga Penelitian dan Pengabdian kepada Masyarakat (LPPM) melalui PNBP Fakultas Sains dan Teknologi Universitas Jambi yang telah mendanai kegiatan ini.

\section{DAFTAR RUJUKAN}

Anzani, S. D., Wignyanto, W., Hindun Pulungan, M., \& Rosallina Lutfi, S. (2016). Natural Dye of Soursop Leaf (Annona muricata L.) for Mori Primissima Fabric (Study: Types and Fixation Concentrations). Industria: Jurnal Teknologi Dan Manajemen Agroindustri, 5(3), 132139. https://doi.org/10.21776/ub.industria.2016.005.03.3

Arif, W. F., \& Marsudi. (2019). Uji Coba Warna Daun Sirih Merah dengan Teknik Pounding dan Steam. Journal of Visual Languages \& Computing, $7(2)$, 73-80. https://jurnalmahasiswa.unesa.ac.id/index.php/va/article/view/29246

Atirza, V., \& Soewondo, P. (2018). Penyisihan Zat Warna Napthol pada Limbah Cair Batik dengan Metode Adsorpsi Menggunakan Adsorben Tanah Liat dan Regenerasinya. Jurnal Teknik Lingkungan, 24(1), 93107. https://ftsl.itb.ac.id/wp-content/uploads/sites/8/2020/04/7-93-106Valerie.pdf

Herlina, M. S., Dartono, F. A., \& Setyawan. (2018). Eksplorasi Eco Printing Untuk Produk Sustainable Fashion. Ornamen Jurnal Kriya Seni ISI Surakarta, 15(2), 118-130. https://jurnal.isiska.ac.id/index.php/ornamen/article/view/2540/2317

Husna, F. (2016). Eksplorasi Teknik Eco Dyeing dengan Tanaman sebagai Pewarna. E-Proceedin of Art \& Design, 3(2), 280-293.

Pudjianti, M. (2019). Ecoprint dan Filosofi Daun (Pertama). Dinas Penerangan Angkatan Laut.

Pujilestari, T. (2014). Pengaruh Ekstraksi Zat Warna Alam dan Fiksasi terhadap Ketahanan Luntur Warna pada Kain Batik Katun. Dinamika Kerajinan Dan Batik: Majalah Ilmiah, 31(1), 31-40. https://doi.org/10.22322/dkb.v31i1.1058

Saptutyningsih, E., \& Wardani, D. T. K. (2019). Pemanfaatan Bahan Alami Untuk Pengembangan Produk Ecoprint Di Dukuh Iv Cerme, Panjatan, 
Kabupaten Kulonprogo. Warta LPM, 21(2), 18-26. https://doi.org/10.23917/warta.v21i2.6761

Saraswati, T. J., \& Sulandjari, S. (2018). Perbedaan Hasil Rok Pias Eco Print Daun Jati (Tectona grandis) Menggunakan Jenis dan Massa Mordan Tawas dan Cuka. E-Journal Unesa, 7(2), 1-7. https://jurnalmahasiswa.unesa.ac.id/index.php/jurnal-tatabusana/article/view/24723

Utaminingsih, A., \& Wike. (2019). Pelatihan Ecoprint bagi Kader PKK Di Desa Tegalweru, Kecamatan Dau, Kabupaten Malang. 28-32.

Wirawan, B. D. S., \& Alvin, M. (2019). Teknik Pewarnaan Alam Eco Print Daun Ubi dengan Penggunaan Fiksator Kapur, Tawas dan Tunjung. Jurnal Litbang Kota Pekalongan, 17, 1-5. https://jurnal.pekalongankota.go.id/index.php/litbang/article/view/101 